\title{
Erratum zu: Hysterie und Hysterese. Die Asylmigration und der Erfolg der Alternative für Deutschland (AfD)
}

\author{
Markus Klein · Frederik Springer
}

Online publiziert: 19. Juli 2021

(C) Der/die Autor(en) 2021

\section{Erratum zu:}

\section{Köln Z Soziol 2020}

https://doi.org/10.1007/s11577-020-00710-2

Der Artikel Hysterie und Hysterese. Die Asylmigration und der Erfolg der Alternative für Deutschland (AfD) von Markus Klein und Frederik Springer wurde ursprünglich Online First ohne „Open Access“ auf der Internetplattform des Verlags publiziert. Nach der Veröffentlichung in Band 72 Heft 3 pp. 455-470 hatten sich der Autor für eine „Open Access“-Veröffentlichung entschieden. Das Urheberrecht des Artikels wurde deshalb in (C Der/die Autor(en) 2021 geändert.

Funding Open Access funding enabled and organized by Projekt DEAL.

Open Access Dieser Artikel wird unter der Creative Commons Namensnennung 4.0 International Lizenz veröffentlicht, welche die Nutzung, Vervielfältigung, Bearbeitung, Verbreitung und Wiedergabe in jeglichem Medium und Format erlaubt, sofern Sie den/die ursprünglichen Autor(en) und die Quelle ordnungsgemäß nennen, einen Link zur Creative Commons Lizenz beifügen und angeben, ob Änderungen vorgenommen wurden.

Die in diesem Artikel enthaltenen Bilder und sonstiges Drittmaterial unterliegen ebenfalls der genannten Creative Commons Lizenz, sofern sich aus der Abbildungslegende nichts anderes ergibt. Sofern das betref-

Die Online-Version des Originalartikels ist unter https://doi.org/10.1007/s11577-020-00710-2 zu finden.

\footnotetext{
Markus Klein $(\varangle) \cdot$ Frederik Springer

Institut für Politikwissenschaft, Leibniz Universität Hannover

Schneiderberg 50, 30167 Hannover, Deutschland

E-Mail: m.klein@ipw.uni-hannover.de

Frederik Springer

E-Mail: f.springer@ipw.uni-hannover.de
} 
fende Material nicht unter der genannten Creative Commons Lizenz steht und die betreffende Handlung nicht nach gesetzlichen Vorschriften erlaubt ist, ist für die oben aufgeführten Weiterverwendungen des Materials die Einwilligung des jeweiligen Rechteinhabers einzuholen.

Weitere Details zur Lizenz entnehmen Sie bitte der Lizenzinformation auf http://creativecommons.org/ licenses/by/4.0/deed.de. 